\title{
RESSIGNIFICAÇÃO DA PESQUISA ESCOLAR: O ALUNO- PESQUISADOR, INVESTIGANDO E PROMOVENDO REFLEXÃO EM SEU MEIO, ATRAVÉS DE GÊNEROS MULTIMODAIS
}

Deuzina Elaine Melo Casteluber
Universidade Federal de Minas Gerais

Patrícia Santos Costa de Resende

Universidade Federal de Minas Gerais

\section{Resumo}

Vivemos em uma sociedade cercada por linguagens icônicas. Compreender essa particularidade da língua é fator fundamental na produção do sentido. $\mathrm{Na}$ escola, elas precisam ser apreendidas pelos alunos para que possam fazer o uso contínuo dessas linguagens. Nesse contexto, a concepção de língua e a mediação do professor são fundamentais para o sucesso escolar. Assim, surge a ideia de ressignificar a pesquisa escolar, tornando o aluno um pesquisador, que promove reflexões. Foram selecionados dois gêneros multimodais, para analisar até que ponto esses gêneros produzidos pelos alunos podem promover reflexão crítica, mediante aos temas encontrados em seu meio. Destacamos os pressupostos de Dell'Isola (2010), Dionísio (2006), Rojo (2004, 2009), Zuin \& Reyes (2010), Barbosa, Mori (2012). Os resultados comprovaram que as atividades interdisciplinares permitiram ao aluno a compreensão e a apreensão do gênero como evento social capaz de atender suas necessidades de leitor e como possibilidade de ler criticamente o mundo.

Palavras-chave: Gênero multimodal; Mediação; Aluno-pesquisador. 


\title{
REFRAMIG RESEARCH SCHOOL: STUDENT-RESEARCHER, INVESTIGATING AND REFLECTION IN PROMOTING YOUR MEANS, BY GENRE MULTIMODAL
}

\begin{abstract}
We live in a society surrounded by iconic languages. Understanding this feature of the language is a fundamental factor in the production of meaning. At school, they need to be seized by the students so they can make the continued use of these languages. In this context, the concept of language and mediation of the teacher are critical to school success. Thus arises the idea to reframe the research school, making the student a researcher who promotes reflections. We selected two genres multimodal, to analyze to what extent these genres produced by students can promote critical reflection upon the themes found in their midst. We highlight the assumptions Dell'Isola (20,010), Dionysius (2006), Rojo (2004, 2009), Zuin \& Reyes (2010), Barbosa, Mori (2012). Results showed that the interdisciplinary activities allowed the students to understand and grasp the genre as social event able to meet your needs as a player and ability to read critically the world.
\end{abstract}

Key words: Gender multimodal; Mediation; Student-researcher. 


\section{Introdução}

Ao longo das últimas décadas a perspectiva de ensino sofreu profundas modificações. Após a criação dos parâmetros curriculares nacionais, o aprendizado que antes priorizava o conteúdo, passa a ser norteado pelas competências e habilidades. Esse novo enfoque de educação ressignifica a formação do aluno, que ultrapassa a ideia de domínio de determinados conteúdos. A atual concepção de ensino prevista pelos parâmetros curriculares nacionais visa à formação de alunos pesquisadores, alunos que saibam pensar, refletir e propor soluções sobre os problemas e questões atuais. Isto é, a formação de seres críticos e participativos, conscientes de seu papel nas mudanças sociais.

Tais transformações ressignificam o processo de ensino-aprendizagem e a relação aluno-professor. Se antes o conhecimento era transmitido pelo professor e o aluno assumia posição passiva de receptor, agora o professor adquire a função de organizador e o aluno desempenha um papel ativo, pois interage e atribui novos significados à informação apreendida. No campo da linguagem, mais especificamente nas aulas de Língua Portuguesa e Redação o trabalho com texto e os gêneros textuais ganham novo enfoque. Mas, diante dessas mudanças fica a pergunta: Como inseri-las, na prática, no dia a dia escolar, a fim de se obter sucesso e não o fracasso na busca da aprendizagem?

Vivemos cercados por diferentes linguagens, em que imagens, sons, desenhos, gestos e expressões faciais se integram em todo o tempo e precisam ser apreendidas pelos alunos para que saibam fazer uso contínuo e adequado dessas novas linguagens e ao mesmo tempo, tenham uma visão “situada da língua em uso", como postula Rojo (2009, p. 90 e 181). No entanto, para que os sujeitos, hoje, possam participar ativamente da sociedade e interagir por meio dessas linguagens, é necessário que os leitores compreendam os diferentes textos à sua volta, que ampliem suas práticas de letramento, isto é, que consigam ir além da decodificação mecânica. Este é apenas o primeiro passo da atividade de leitura. Ler é saber ir além do ato de decodificar. É saber interagir com a informação lida,

Olh@res, Guarulhos, v. 2, n. 1, p. 396-421. Maio, 2014. 
percebendo o não dito, os elementos implícitos. É saber ressignificar o texto e utilizá-lo em diferentes práticas e contexto sociais. O ensino de língua pautado nesse princípio favorece a formação do aluno-pesquisador, consequentemente o sucesso escolar.

Contudo, a ampliação do grau de letramento dos sujeitos e a formação de leitores autônomos e bem sucedidos no processo de comunicação depende da perspectiva de ensino de língua e texto adotado pelo professor como também, dos diferentes recursos didáticos utilizados durante as aulas. Qualquer ação no ensino é orientada por concepções. São essas concepções que levam os professores a optarem por determinados conteúdos e não outros, por determinadas práticas e não outras, em sala de aula. Se a leitura nem sempre é entendida como processo de construção de sentidos, isso se deve às concepções adotadas pelo educador. O texto não pode ser visto como é um produto pronto, acabado, mas sim, construído na interação entre autor-texto-contexto-leitor.

Escolher livros aprovados pelo PNLD, elaborar atividades complementares que dialogam com o livro adotado são pontos importantes para o desenvolvimento do grau de letramento do indivíduo. Tais cuidados contribuem para a formação de leitores autônomos e bem sucedidos no processo de comunicação. É importante ressaltar que o livro didático não pode ser o único instrumento de aprendizagem, posto que a aula de Língua Portuguesa não pode limitar-se apenas às atividades do livro adotado. Este é um material auxiliar, um recurso a mais para o ensino da língua.

Quando a escola coloca em prática essas concepções propicia aos alunos a oportunidade de exercer a cidadania, uma vez que é direito de todo indivíduo entender a grande variedade de textos, que veiculam inúmeras e diferentes linguagens construídas por meio de gêneros textuais. Favorece também, a formação de seres críticos, participativos e conscientes de seu papel nas mudanças sociais. É essa postura do educador diante do processo que determina o sucesso ou não da aprendizagem.

O trabalho do professor é essencial para o processo de apropriação da língua escrita, visto que é o responsável por mediar o conhecimento cotidiano e o conhecimento científico. É fundamental que o professor faça intervenções

Olh@res, Guarulhos, v. 2, n. 1, p. 396-421. Maio, 2014. 
introduzindo um novo parâmetro ao saber prévio do aluno, levando em consideração que esse conhecimento prévio, muitas vezes, pode estar aquém das exigências que a compreensão do texto impõe. Essa mediação faz com que o leitor vá além do que já interiorizou e permite que construa novas hipóteses sobre o que pensa e vive.

A partir do exposto e pensando na ressignificação da figura do professor como mediador do conhecimento, surgem as seguintes perguntas: Como o educador pode promover, nos alunos, a visão "situada da língua em uso", por meio diferentes leituras e produções próximas do cotidiano destes? Como, por meio destes textos, promover reflexão, construção de sentido na interação dos sujeitos envolvidos no processo? Tais aprendizagens podem propiciar o sucesso escolar, pois favorece a visão do aluno como sujeito, agente de suas relações sociais e sujeito de sua relação com o mundo, aquele que utiliza o gênero como prática social constituída.

Quando investigamos nos livros didáticos das séries finais do Ensino Médio, o quanto as atividades propostas pelos gêneros multimodais destacadas permitem ao aluno a compreensão do gênero como evento social real capaz de atender suas necessidades de leitor e até que ponto a apreensão do gênero possibilita uma leitura critica do mundo, buscamos mostrar o gênero como um evento social, capaz de refletir a sociedade em que o educando vive e como uma pratica social dialógica, mediada pelo professor, através da qual eles podem sim se ressignificar através dele. Como postula Rojo (2004, p.20) “é necessário trazer o texto para a vida e colocá-lo em relação com ela; é preciso discuti-lo, dialogar com ele, replicando-o e avaliando posições e ideologias que constituem seus sentidos".

Assim, diante das análises dos textos produzidos pelos alunos, temos por objetivo verificar a importância do professor como mediador do processo de formação do aluno-pesquisador. Através do gênero multimodal (Cartum e H/Q) selecionado é possível conscientizar os jovens e adolescentes da necessidade de se posicionar como cidadão perante o problema identificado, ressignificando-o, e quem sabe, promovendo novas formas de abordá-lo, por meio dos diferentes recursos persuasivos apresentados por esses gêneros, tão reais, tão próximos e tão atuais. A escolha pelo gênero multimodal se

Olh@res, Guarulhos, v. 2, n. 1, p. 396-421. Maio, 2014. 
deu por sua diagramação, pela constituição argumentativa desses textos e por suas marcas de posicionamento do autor, que oportunizam ao aluno/leitor interagir por meio dele.

A entrada dos gêneros textuais, em especial os gêneros multimodais, na sala de aula, introduz novos horizontes ao ensino e à aprendizagem da leitura e da escrita. Textos dessa natureza necessitam ser lidos, argumentados e discutidos, dando a oportunidade de revelar estilos próprios de linguagem que reflitam as relações entre os elementos dialógicos textuais, levando à seleção de conteúdos e objetivos (explícitos e implícitos) que culminarão na sua divulgação. Enfim, a proposta é apresentar e defender o valor da escrita desses gêneros, pois neles são delineados os parâmetros de produção e circulação nas práticas sociais de linguagem, como observa Marcuschi (2008).

\section{Algumas concepções na abordagem sociointeracionista}

Para refletir sobre os questionamentos propostos, este estudo baseia-se na abordagem sociointeracionista, perspectiva que considera o contexto e a interação entre os sujeitos. Nessa abordagem a leitura é entendida como o processo de construção de sentido, que vai além da decodificação e que permite aos sujeitos sua participação mais ativa numa sociedade letrada. É, portanto, uma atividade interativa, complexa de produção de sentidos construídos a partir de elementos linguísticos presentes no texto. O sentido de um texto é construído na interação texto-sujeitos e não é algo que preexista a essa interação. O leitor assume papel ativo, pois constrói o sentido textual através de estratégias, tais como: seleção, antecipação, inferência e verificação, entre outras operações mentais. Ao assumir esse papel, torna-se proficiente, crítico, aquele que sabe fazer o uso da língua em diferentes situações de comunicação. Para Soares (2001, apud DELL'ISOLA, 2001, p. 8) o texto não preexiste a sua leitura, e esta não é aceitação passiva, mas é construção ativa. O texto se constitui através do processo desencadeado pela leitura. Segundo a autora, o que é reiterado por Cafiero (2010, p. 12), o texto e o leitor são o ponto de partida para a

Olh@res, Guarulhos, v. 2, n. 1, p. 396-421. Maio, 2014. 
compreensão, e esta só se efetiva, isto é, torna-se produção de sentido, na interação de ambos.

O sucesso na formação do aluno-pesquisador depende da concepção ensino adotada pelo professor. O aluno só será crítico, proficiente e consequentemente pesquisador se, através da mediação deste, aprender a estabelecer objetivos de leitura e a redefini-los ao longo do texto lido. Através deles, poderá verificar o que compreendeu e o que falta compreender sobre a informação lida, interagindo assim com o texto. De acordo com os estudos de Kleiman (2008b), conduzir o aluno a conceber a leitura como um processo de interação, que ocorre via texto, entre leitor e autor é um dos passos para a formação de um leitor proficiente. Quando o aluno é motivado a formular objetivos, hipóteses e a levantar expectativas sobre o texto que será lido, mobiliza seus conhecimentos prévios, apreende as pistas formais deixadas pelo autor, interagindo e construindo um significado global para o texto em estudo. Nessa mesma perspectiva, Marcuschi $(2008,2552)$ afirma que "compreender é essencialmente uma atividade de relacionar conhecimentos, experiências e ações num movimento interativo e negociado".

Ainda nessa perspectiva, Vygotsky, Bakthin e Freire, (apud Reyes e Zuin, 2010, p.32) concebem a linguagem como um processo de interação e constituição das relações sociais e, portanto, da constituição dos indivíduos e de sua consciência. Por ser um processo de interação é necessário que os professores, como mediadores intencionais, tenham o conhecimento da língua e da linguagem enquanto criação viva, enquanto a principal mediadora do homem com o mundo, a fim de que possam mudar efetivamente as relações de ensino-aprendizagem.

Cabe salientar ainda a necessidade de o professor, como mediador, em primeiro lugar, dominar os conteúdos e os gêneros que sistematizem o saber científico de forma a facilitar a aprendizagem dos alunos, sem esquecer-se de levar em consideração o contexto ao qual eles pertencem. Em segundo lugar, como postula Freire (2006), deve-se em qualquer processo de ensino aprendizagem, conscientizá-los de que, enquanto sujeitos, são eles que constroem a história. Ademais, sendo o educador um agente de letramento,

Olh@res, Guarulhos, v. 2, n. 1, p. 396-421. Maio, 2014. 
conforme Souza e Serafim (2012, 19), ele deve mobilizar estratégias adequadas para que seus aprendizes possam ampliar seu letramento por meio de leituras diversificadas. Afinal, quanto mais informações novas apreendidas, maior será o aprendizado. Somente assim o professor será um mediador relevante deste processo e estará cumprindo a sua função política, socializadora, isto é, dando acesso à produção humana (REYES e ZUIN 2010, p. 85).

Nessa mesma visão, Rojo (2004, p. 11) sugere que o estudo de língua seja associado à noção do gênero. É importante, segundo a autora, “enfocar, em sala de aula, o texto em seu funcionamento e em seu contexto de produção/leitura, evidenciando as significações geradas mais do que as propriedades formais que dão suporte a funcionamentos cognitivos".

Numa proposta interativa de ensino da língua, nesse contexto, ganha sentido a noção de gênero como ponto de partida e ponto de chegada. Em sua concepção teórica, Bakhtin (2003, p. 262) afirma que cada campo de utilização da língua elabora seus tipos relativamente estáveis de enunciados, os quais denominam: gêneros do discurso. Segundo Marcuschi (2008, p. 155), gêneros são "os textos que encontramos em nossa vida diária e que apresentam padrões sociocomunicativos característicos definidos por composições funcionais, objetivos enunciativos e estilos concretamente realizados na integração de forças históricas, sociais, institucionais e técnicas". Sob essa ótica a compreensão de um texto estará sempre associada à compreensão do funcionamento do gênero textual, visto que todo texto pressupõe um gênero.

Trabalhar gênero em sala de aula, segundo os Parâmetros Curriculares Nacionais, é imprescindível, pois os alunos devem ser capazes de lidar com diferentes gêneros "combinando estratégias de decifrações com estratégias de seleção, antecipações, inferências e verificações.” (BRASIL, 1998, p. 101-104), capazes de produzir textos coerentes e coesos considerando o leitor e o objeto da mensagem; identificar o gênero como suporte que melhor atende à intenção comunicativa. Contudo, esse trabalho precisa ser planejado. De acordo com Dolz e Schneuwly (2004), trabalhar com gêneros requer a elaboração de um modelo didático do gênero a ser ensinado,

Olh@res, Guarulhos, v. 2, n. 1, p. 396-421. Maio, 2014. 
construído a partir da análise das características comuns de um grupo de textos. Trabalhar nessa perspectiva possibilita aos alunos o desenvolvimento de capacidades de linguagens globais como narrar, relatar, argumentar, expor e descrever ações.

Nesse sentido, o trabalho com o gênero multimodal, além de desenvolver as capacidades descritas anteriormente, conduz o aluno à compreensão da linguagem icônica e icônicas-verbais, isto é, através desse gênero é possível levá-lo, através da mediação do professor, a perceber que as imagens, sons, gestos e expressões faciais se integram com um propósito, com um sentido, o que é essencial para o desenvolvimento do letramento. Essa percepção permite, segundo Rojo (2009, p. 90 e 181), "que o aluno tenha a competência linguística para atender as demandas e diferentes práticas linguísticas sociais", propiciando uma visão "situada da língua em uso".

Dionísio (2006), nessa mesma concepção, defende que essas "representações e imagens não são meramente formas de expressão para divulgação de informações ou representações naturais, mas são acima de tudo textos, que revelam as nossas relações com a sociedade e com o que a sociedade representa. Por conseguinte, se os gêneros servem para atender as necessidades, propósitos comunicativos de quem fala, de quem os utiliza, por que não trazer para sala de aula, por meio do livro didático, através da intervenção do professor e demais atividades escolares, as práticas desses gêneros multimodais, ampliando assim o letramento dos alunos e permitindo-lhes múltiplos letramentos?

Segundo Fairclough (2001[1992], p.23), é conveniente “estender a noção de discurso a outras formas simbólicas, tais como imagens visuais e textos que são combinações de palavras e imagens". Isto se justifica porque na contemporaneidade as imagens passam a compor o sentido dos textos juntamente com a modalidade escrita, com forte carga semântica e ideológica, deixando de apresentar caráter meramente ilustrativo, cabendo, portanto, investigar os textos como produtos de processos ideológicos que pertencem aos discursos como eventos sociais completos centrados na relação entre as pessoas.

Olh@res, Guarulhos, v. 2, n. 1, p. 396-421. Maio, 2014. 
Ressignificação da pesquisa escolar: o aluno-pesquisador, investigando e promovendo reflexão em seu meio, através de gêneros multimodais

\section{A linguagem multimodal: Histórias em quadrinhos e Cartum}

A linguagem multimodal é aquela que apresenta diferentes modos de se expressar, diferentes recursos gráficos, imagéticos, gestuais, entre outros. Conhecer essa linguagem é importante, pois permite aos alunos a ampliação do letramento. Entretanto, segundo Lemke

(2009, p.269, apud Dionísio) para que gêneros multimodais sejam inseridos na escola, é preciso, através da mediação do professor, levá-los a perceberem características próprias desse gênero. As perguntas respondidas no quadro abaixo conduzem à compreensão de aspectos preponderantes desse gênero. Organizar o ensino dessa forma permite ao aluno conhecer não só as características do gênero, mas o seu funcionamento. O que vai ao encontro de Bakhtin que afirma que para se dominar um gênero é preciso conhecê-lo.

Quadro 1 - Características dos gêneros Cartum e HQs na perspectiva de Dionísio (2006, p.140)

\section{Gêneros: Cartum e História em quadrinhos}

O que é? Gênero discursivo que consiste numa reação à situação vigente na sociedade manifestando questionamentos e satirizando fatos, comportamentos, pessoas.

Qual é o propósito? Criticar elementos da realidade, divertindo, conscientizando ao mesmo tempo.

Onde e quando circula? Em jornais e revistas, impressos ou virtuais; de acordo com a periodicidade do veículo; circulam diariamente, semanalmente, quinzenalmente, mensalmente.

Quem lê? O cartum principalmente adultos, com nível médio superior. Pessoas com amplo conhecimento enciclopédico e atualizadas. Já as Histórias em quadrinhos abrangem todos os públicos.

Possível influência na leitura - Conscientização e desenvolvimento do senso crítico e do senso de humor. O Cartum diferentemente da charge não "envelhece" porque ele é atemporal. Ele é um texto híbrido misto de linguagem verbal e não-verbal, linguagem persuasiva, única cena, tematizando situações do cotidiano, especialmente questões universais e de diferentes temáticas. De alto teor ideológico.

O gênero HQs, de acordo com Cirne (2000, p. 23-24, apud Mendonça), é definido como "uma narrativa gráfico-visual, impulsionada por sucessivos cortes, cortes estes que agenciam imagens rabiscadas, desenhadas e/ou pintadas". São, portanto, semióticas ou multimodais. Têm uma estrutura mais curta (até 4 quadrinhos) e podem ser sequenciais. Seu propósito é satirizar aspectos econômicos e políticos do país, embora não sejam tão datadas como a charge. Produz humor através de estratégias discursivas. Atualmente, permanecem nos jornais e encontram-se em outros veículos

Olh@res, Guarulhos, v. 2, n. 1, p. 396-421. Maio, 2014. 
midiáticos, tais como, gibis e revistas de diferentes públicos. Circulam diariamente, semanalmente, quinzenalmente ou mensalmente.

Diferentemente da charge e do cartum, as tiras ou HQs podem, além de atrair os leitores infantis e juvenis, ter uma função didática, utilizadas para dar instruções ou para persuadir, em campanhas educativas. São normalmente lidas para divertir e para inteirar os leitores acerca de críticas e temas polêmicos e, de certo modo, formar opinião. É semelhante ao cartum, por ser atemporal, e diferente da charge.

A HQs ou tirinha também é um texto híbrido-misto, de linguagem verbal e não-verbal, podem apresentar, além de sequências narrativas, sequências características de outros tipos textuais, como a argumentação e a injunção. É um gênero icônico verbal narrativo, sua progressão temporal se realiza quadro a quadro. Apresenta quadros, balões e/ou legendas, nos quais são inseridos os textos verbais.

$\mathrm{O}$ cartum e a tira diferenciam-se, ainda que ambos compõem-se de um ou mais quadrinhos com uma sequência narrativa. Essa sequência é opcional para o cartum e obrigatória para a HQs, a qual conta com personagens fixos, conforme Mendonça (2007, pp.197-203).

Quanto aos diversos usos que as HQS podem conceber, segundo Eisner (1999, p.136-143, apud Mendonça, 2007 p. 205), “as HQs podem se manifestar em diferentes usos, como por exemplo: serve para a) entreter, b) dar instruções técnicas, c) condicionamento de atitudes e d) Story Boards (usadas para fazer a ponte entre o roteiro do filme e a fotografia final, na publicidade e no cinema)".

O conhecimento semiótico, aqui entendido como multimodal, passa por quatro níveis: o discurso, a produção, a distribuição e o design ${ }^{1}$, de acordo

\footnotetext{
${ }^{1} \mathrm{O}$ termo design, no âmbito da multimodalidade, designa os próprios recursos semióticos ou o uso desses recursos propriamente ditos. É a combinação de todos os modos semióticos utilizados que faz o design; a produção pode ser considerada como um trabalho físico de articulação do texto; a organização da expressão ou do meio de execução do que foi elaborado, do design, um "artefato semiótico" (Kress, 2001 b: 6 )a forma como um material é produzido para ser distribuído também interferiria na interpretação do leitor, ou seja, na leitura para a produção de significado, pois assim como a produção, a interpretação, também pode ser considerada um trabalho físico que se materializa através de todos os órgãos sensoriais; a distribuição é a forma como irá ser veiculado o produto/ peça para o mercado; é a distribuição literal desse produto para ser comercializado, em um dado suporte, como por exemplo, revistas, jornais, camisetas, entre outras muitas formas de veiculação.
}

Olh@res, Guarulhos, v. 2, n. 1, p. 396-421. Maio, 2014. 
com Kress \& van Leeuwen ${ }^{2}$. É importante ressaltar que todo ato semiótico tem conteúdo ideológico, pois expressa alguma ideia que vai se definir de acordo com outras regras sociais que estão por trás desse pensamento ou do indivíduo comprometido com esse ato.

Tanto o Cartum, quanto as HQs possuem autoria e são datados, elementos esses importantes no processo de compreensão. Para entender esses gêneros em sua totalidade, é interessante observar a ideologia que norteia o autor e o contexto histórico em que foram produzidos. Contudo, essas informações nem sempre são cogitados pelo livro didático e precisam ser ressaltas pelo educador.

Esses autores ressaltam a importância de se compreender o que está além do verbal: as expressões faciais, gestos, imagens faciais, música, sons, entre outros modos semióticos. Segundo os autores, a imagem, ou o seu reconhecimento é algo específico da cultura da qual ela advém. Dessa forma, "a utilização da imagem dependerá de contextos sociais específicos ou do potencial semiótico de textos que poderão ou não atingir muitos falantes em muitos contextos culturais" (Pimenta, 2007, p.171).

\section{Composição do corpus e critérios de análise}

Aproximar a escrita escolar da não escolar fortalece os vínculos existentes, dentro e fora da escola. Isso possibilita o desenvolvimento de um trabalho mais eficiente e o entendimento, por parte dos alunos, do poder da leitura e da escrita e seu uso competente na sociedade.

Entretanto, para que esses novos saberes, sejam inseridos na escola, é preciso que os mediadores estejam plenamente conscientes da existência deles e, além disso, compreendam alguns aspectos preponderantes no ensino dos gêneros multimoldais tais como: Que recursos empregam? Como eles podem ser integrados um ao outro? Como são tipicamente formatados? Quais são os valores e limitações deles? Que gênero utilizar para determinado tema? Qual é a maneira mais adequada de abordá-lo? Onde e como buscar as formas mais adequadas de interação? Conduzir o aluno ao

\footnotetext{
${ }^{2}$ KRESS, G. e vanLEEUWEN, T. Reading Image: the Grammar of Visual Design. Londres: Routledge, 1996.

Olh@res, Guarulhos, v. 2, n. 1, p. 396-421. Maio, 2014.
} 
entendimento dessas questões é fundamental no processo de compreensão dos gêneros multimoldais.

Nessa perspectiva, surge por um lado, a oportunidade de interagir escola/leitura/linguagem/sociedade, aproximando a escrita escolar da não escolar, fortalecendo vínculos existentes, dentro e fora da escola; por outro lado, possibilita aos alunos/leitores entender o poder da leitura e da escrita, tendo ainda a motivação para usá-los de forma mais competente na sociedade. Assim, surge a grande questão: Como através da linguagem verbal e não verbal o leitor/escritor da Rede pública estadual do $2^{\circ}$ e $3^{\circ}$ anos pode, através da mediação do professor, intervir em um problema social de jovens da mesma idade do seu bairro?

Sendo um trabalho interdisciplinar, que disciplinas contribuiriam na elaboração dos temas, das atividades, dos gráficos e das entrevistas? Como poderiam ser feitas as divulgações finais dos textos? Quem reproduziria e distribuiria? Onde seriam veiculados os textos? Esse tipo de abordagem se justifica pelo valor atribuído pela sociedade à linguagem, principalmente no que tange à leitura e quanto aos gêneros escolhidos porque permitem à participação efetiva do aluno na mídia como leitor/escritor, cidadão ativo, participativo de sua comunidade.

Com a mediação de professores de Geografia, na montagem e leitura de gráficos; Biologia, nas pesquisas, dados e orientações sobre os temas de saúde levantados; Sociologia, na elaboração de questionários e importância social dos textos na comunidade e de Língua Portuguesa, na aprendizagem e diálogo com os gêneros, bem como a sua estrutura composicional, estilo e função social, leitura/produção, releitura e reescrita dos gêneros selecionados foi proposto um desafio aos alunos do $2^{\circ}$ e $3^{\circ}$ anos do Ensino Médio da Escola Estadual Flávio dos Santos. Estes deveriam escolher um problema social de sua comunidade relacionado aos jovens na faixa etária entre 14 e 18 anos e junto com os professores mediadores buscar intervenção para o problema através de um gênero multimodal (cartum e HQ). Para tanto, deveriam responder a pergunta-problema: Como através da Linguagem multimodal, os alunos, mediados pelos professores, poderiam intervir nos problemas salientados? Como divulgar os trabalhos nos bairros?

Olh@res, Guarulhos, v. 2, n. 1, p. 396-421. Maio, 2014. 
Tal atividade foi trabalhada em três meses. Após a leitura de vários textos pertinentes aos temas escolhidos e atividades pertinentes às formas relativamente estáveis dos gêneros multimodais selecionados, os alunos elaborariam textos que materializassem as opiniões levantadas do grupo bem como suas soluções ou possibilidades de intervenção ao problema, respeitando cada particularidade do gênero escolhido. Por um lado, foi pedido que os textos trouxessem reflexões e possibilitassem aos interlocutores de leituras implícitas e desejo de participar ativamente do processo de mudança social. É como postula Fairclough (2003, p. 18) devemos "lançar luz sobre os problemas que as pessoas enfrentam por efeito de formas particulares da vida social e buscar recursos dos quais essas pessoas possam se valer para superar esses problemas".

Por outro lado, perceber que o discurso como prática social pode e deve intervir em situações opressoras e pode mudar, ou seja, podem ser mudadas, porque são criações sociais e, como tal, são passíveis de serem transformadas socialmente. Ademais, ele como sujeito social, como alunopesquisador não se contente em apenas descrever e teorizar os problemas sociais encontrados em sua comunidade, mas antes, como cidadão ativo sinta o desejo de participar ativamente dos processos de mudança e mais uma vez dialogando com Fairclough (2001[1992], apud Rocha, 2007), vale salientar que a linguagem não é apenas uma forma de representação do mundo, mas também de ação sobre o mundo e sobre o outro.

Buscando respostas para as questões deste trabalho, à luz dos fundamentos teóricos apresentados no item anterior, foram analisados, especificamente, dois textos multimodais. Para tanto, alguns critérios foram estabelecidos aos alunos: 1. Que o trabalho tivesse coerência e coesão; 2. Fosse relacionado ao tema proposto; 3. Fosse uma releitura de algum gênero-modelo; 4. Apresentasse a voz do grupo, autoria e uma possível intervenção ao problema salientado; 5. Respeitasse a identidade e individualidade, por isso as pesquisas seriam orientadas por Instituições dos bairros pesquisados; 6 . Tivesse ética nas abordagens; 7. Fosse divulgado nas mesmas Instituições pesquisadas com aval destas.

Olh@res, Guarulhos, v. 2, n. 1, p. 396-421. Maio, 2014. 
Na constituição do corpus, foi utilizada, como fonte documental, a coleção Português linguagens: Literatura, Produção de Texto e Gramática, de William Roberto Cereja e Thereza Cochar Magalhães, em sua $7^{\mathrm{a}}$ edição, publicada em 2010, pela Editora Saraiva, aprovada no PNLD 2012. Mais especificamente em seu volume 2 p.30-32. Além de dois textos multimodais elaborados pelos alunos e veiculados em sua comunidade, além da escola.

A ideia deste trabalho surge para atender uma expectativa suscitada por uma atividade proposta pelo livro didático, acima mencionado, em que em sua seção Produzindo o texto de campanha publicitária, o Manual Didático (doravante MD) solicita uma produção de um cartaz publicitário. Diante da atividade e pensando na ressignificação do ensino, nos propomos adequar o conteúdo programático, no caso o gênero cartaz publicitário, ao contexto, a realidade vivenciada pelos alunos.

A atividade proposta pelo MD apresenta um folheto publicitário denunciando o Tráfico Internacional de mulheres publicado pelo Ministério da Justiça com apoio das Nações Unidas, seguido de atividades, organizadas em 8 questões, que trabalham o gênero evidenciando a finalidade, o perfil dos interlocutores, o tema, o suporte, estrutura e linguagem. O que se pode pressupor é que antes de produzir o texto publicitário o MD orienta o aluno/leitor em relação à constituição formal do gênero, bem como sua função social. Para dar continuidade à atividade, o MD apresenta, conforme quadro a seguir algumas propostas de produção.

Quadro 2 - Atividade proposta pelo MD

1-Individualmente ou em grupos, escreva o texto de uma das seguintes campanhas comunitárias, dirigidas à comunidade escolar ou à comunidade do bairro onde se localiza sua escola ou, ainda ao público geral.

- Doação de livros de literatura infantil e juvenil para a biblioteca da escola.

- Banco de óculos em prol de uma entidade assistencial de seu bairro ou da cidade.

- Doação de alimentos e agasalhos para uma entidade de seu bairro ou da cidade.

- Doação de alimentos e agasalhos para uma entidade assistencial de sua cidade ou para pessoas vítimas de enchentes

- Brinquedos e roupas em prol de crianças carentes de uma escola de seu bairro ou da cidade.

Siga as instruções dadas à proposta anterior e, ainda:

a) Crie um título chamativo, que ressalte a intenção da campanha.

b) Reúna imagens (fotos ou ilustrações) ao texto, de forma que elas sirvam de apoio e chamamento aos itens fundamentais da campanha.

Olh@res, Guarulhos, v. 2, n. 1, p. 396-421. Maio, 2014. 
Conforme podemos verificar, após trabalhar as atividades pertinentes à constituição do gênero, o MD solicita aos alunos, em uma das questões propostas, que escrevam um cartaz publicitário dirigido à comunidade escolar ou à comunidade do bairro onde se localiza sua escola, ou, ainda, ao público em geral, sobre uma das campanhas sugeridas.

À luz dessas considerações, a atividade sugerida pelo livro didático foi ressignificada visando, em primeiro lugar, a interação aluno/leitor/texto/contexto, com as diferentes linguagens que o cercam, despertando-lhe o interesse pela pesquisa em si e pelo ato de pesquisar. Em segundo lugar, aproximação, interação da escrita escolar da não escolar, fortalecendo vínculos existentes, dentro e fora da escola. Em terceiro lugar, o desenvolvimento de um trabalho mais eficiente, em que os alunos entenderão o poder da leitura e da escrita, tendo motivação para usá-las de forma mais competente na sociedade.

Inicialmente, os alunos produziram o gênero cartaz publicitário, conforme proposto no MD. Contudo, ao longo do processo, optaram pela HQs e a charge, objetivando uma interação maior com público alvo. Dos 16 (dezesseis) trabalhos apresentados pelos grupos, selecionamos dois. Para chegar a esse recorte, fizemos uma análise de todos os textos produzidos. Os textos que não apresentavam os critérios pré-estabelecidos, ou apresentavam o seu foco de análise apenas na estrutura dissertativo-argumentativa e não no gênero em si, foram eliminados. Os trabalhos selecionados destacam-se por sua multimodalidade na organização, conteúdo temático e função social, que atendem a diferentes interlocutores e a possibilidade que eles têm de desenvolver capacidades que buscamos nos alunos como leitores críticos e atores sociais.

As figuras a seguir representam as duas produções selecionadas. Essas produções objetivam chamar a atenção dos interlocutores para um grave problema social vivenciado pela comunidade. Tal problema tem crescido assustadoramente entre os jovens adolescentes nos bairros e no ambiente escolar a ponto de ser palco de pesquisa e possível intervenção destes. A figura 1 apresenta o gênero quadrinhos e teve como tema a gravidez na adolescência. Já a figura 2, com o tema saúde pública, é representada

Olh@res, Guarulhos, v. 2, n. 1, p. 396-421. Maio, 2014. 
através da charge. Diante desses trabalhos surgiu outro questionamento: Da forma como os textos foram elaborados, desenvolve-se a capacidade de o sujeito leitor compreender o texto e perceber as opiniões que são construídas por meio dele?

Figura 1 - Texto produzido pelos alunos - Quadrinhos
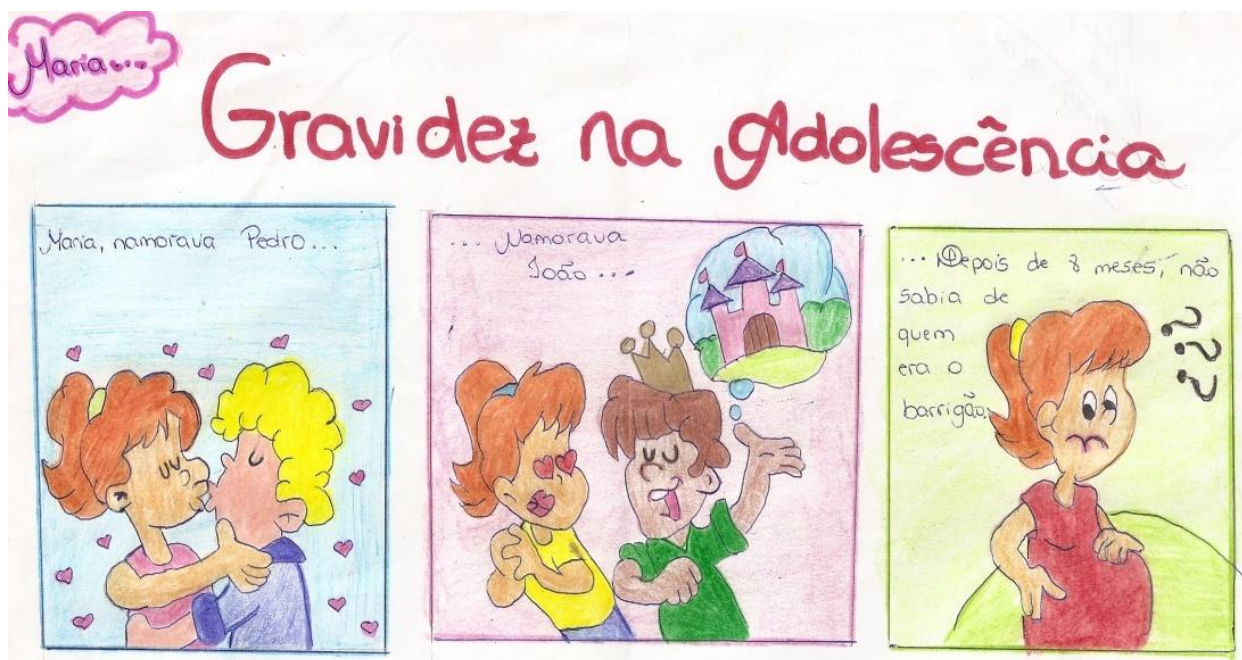

Figura 2 - Texto produzido pelos alunos - Cartum

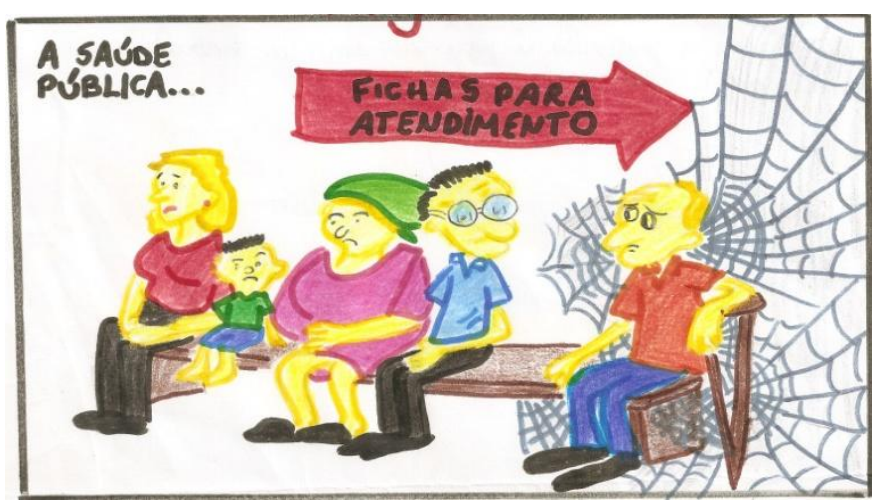

Portanto, a motivação deste trabalho está relacionada ao desejo de verificar como se processa, hoje, o trabalho com a leitura de gêneros multimodais em sala de aula, e até que ponto a escola, os professores e o MD trabalham numa perspectiva a incentivar a pesquisa no aluno/leitor; até que ponto esses mediadores possibilitam ao aluno o diálogo com gêneros midiáticos e possibilitam o uso destes em seu tempo real?

Olh@res, Guarulhos, v. 2, n. 1, p.396-421. Maio, 2014. 


\section{Análise e resultados das atividades propostas}

Algumas etapas nortearam esse trabalho. Na primeira os alunos em equipe deveriam escolher um problema social polêmico, real e atual que envolvesse jovens entre 14 a 18 da comunidade deles. Em seguida, deveriam escolher um gênero multimodal que melhor adequasse o tema. Para tanto os alunos teriam que elaborar o trabalho a partir de uma pergunta-chave: Como através da linguagem multimodal o aluno-leitor-pesquisador pode contribuir criticamente e quem sabe até intervir em um problema social de sua comunidade? Foi também orientado aos alunos que buscassem ajuda em instituições sociais: igrejas, posto de saúde e escolas. Tal medida foi tomada para resguardar a identidade dos entrevistados.

$\mathrm{O}$ objetivo não era denunciar as pessoas e sim o problema, buscando a possibilidade de como jovem da mesma comunidade poderia intervir no problema. O trabalho deveria ser veiculado nas instituições visitadas. Cada professor ficou responsável por uma atividade: Biologia trabalhou os temas, através de palestras, questionamentos. Geografia orientou na confecção dos gráficos e no levantamento estatístico a cerca de quantos jovens do bairro estariam envolvidos no problema destacado. Sociologia orientou-os em como abordar o problema de forma ética e como deveriam apresentar o trabalho nas instituições. Língua Portuguesa trabalhou os gêneros quanto à forma composicional, tema, estilo função social.

Foi utilizada a sequência didática de Dolz e Schneuwly no ensino dos gêneros selecionados. A forma, os temas, a linguagem e a função social do gênero foram trabalhados. Para tanto foram utilizadas como fonte de análise os parâmetros de Antunes, para quem o texto deve ser analisado tanto nos aspectos globais como nos pontuais. Foram também utilizados alguns critérios de análise de Kress e Van Leenson, bem como Thompson e Fairclough quanto ao tema, forma composicional e ideologia, claro que em uma linguagem acessível e sem nomeá-los. O trabalho teve grande repercussão dentro e fora do ambiente escolar. Alguns alunos se empolgaram e criaram blogs.

Olh@res, Guarulhos, v. 2, n. 1, p. 396-421. Maio, 2014. 
O trabalho desenvolvido com os alunos demonstrou que é possível promover e incentivar a interação social via mediação escola x comunidade, a fim de despertar no aluno o desejo pela pesquisa. Ressignificou a atividade com a pesquisa, mostrando que pesquisar é ir além do "recortar" e "colar". É, segundo Larrousse (2001, p.761) "buscar, investigar para descobrir novos conhecimentos, recolher elementos para o estudo, inquirir." Ademais, é mostrar a importância e poder da linguagem, quando bem utilizada para atender as necessidades sócio-comunicativas.

\section{Como a análise foi realizada}

Segundo Antunes (2010, p. 45), analisar pressupõe "separar elementos" de um conjunto, e, em um texto, "nada é separável totalmente". Tudo se imbrica, entrelaça, interdepende. Mesmo que ele permita uma análise mais focalizada de um ou outro aspecto particular, o foco do entendimento deve ser essa dimensão global. Segundo a autora, nada no texto é absolutamente particular, porque no sentido de cada unidade constitui um elo do sentido maior expresso pelo todo. Todos os textos são passiveis de análise, logo todos devem ser ensinados, independentemente do tipo, gênero, tamanho, função, textos verbais, não verbais, mistos, multimodais (imagens, charges, histórias em quadrinhos, gráficos, tabelas mapas).

Analisar um texto significa considerar todos os recursos, tanto os que se materializam linguisticamente, quanto outros responsáveis por sua funcionalidade sociointerativa. A análise pode ocorrer através da observação do texto como um todo, isto é, de sua dimensão global, ou apenas de partes específicas, de seus aspectos pontuais. Contudo, o importante a considerar é que o texto é o ponto de chegada e o ponto de partida, é o objeto dos estudos, das análises, das descrições (BRASIL 1998; CAFIERO, 2010, DELL'ISOLA, 2001; MARCUSCHI, 2001, GERALDI, 2006).

À luz dessas considerações e baseadas em Antunes (2010, p. 56-58) é que propomos uma análise dos textos e das atividades de compreensão observando, primeiramente, a dimensão global para, posteriormente, focar

Olh@res, Guarulhos, v. 2, n. 1, p. 396-421. Maio, 2014. 
circulação. É nessa perspectiva que Fowler (1991, apud PINHEIRO, 2002, p. 277) afirma que "cada gênero emprega estratégias textuais específicas geradoras de expectativas de um tipo particular de experiências discursivas, de uma parte do mundo representado".

À luz dessas considerações, vale salientar, nesse ensejo, que Kress e van Leeuwen, Fairclough e Thompson apresentam categorias importantes de análise no que tange à modalidade visual, verbal e construção ideológica dos gêneros multimodais, que valem a pena serem ressaltadas (quem sabe em uma próxima análise).

Diante do exposto, o primeiro texto, "Gravidez na Adolescência", pertence ao gênero argumentativo (humorístico) opinativo, que, normalmente, servese de mais de um tipo de linguagem a verbal e a visual, de maneira que uma completa a outra, apoiando, refutando ou reforçando à outra. Além disso, negocia tomada de posição, através de argumentos, para persuadir o interlocutor. O segundo texto, "A saúde Pública" consiste em um texto explicativo, que em sua constituição composicional apresenta um cartum como argumento central para demonstrar que o texto não se limita à linguagem verbal, mas se estende a outras modalidades não verbais, valorizando também outras expressões como as faciais, as diagramações, como igualmente significativas na construção do texto crítico capaz de persuadir ou seduzir o interlocutor.

\section{Análise na perspectiva de Antunes}

Apresentamos a seguir, um quadro sob a perspectiva de Antunes (2010), retratando a síntese dos critérios utilizados para a análise da dimensão global dos textos selecionados. Em função de nossos dados, foi necessário redefini-la, adequando-a em relação aos gêneros que estamos analisando.

Na HQs, na Charge, podemos perceber o universo de referência do texto. As linguagens verbal e não verbal trazem ao leitor a informação de que o texto parte de um fato real, concreto e do cotidiano do aluno.

A unidade semântica é construída por meio da disposição dos quadros: três no primeiro; um no segundo e um no terceiro e pelo esquema de composição dos próprios gêneros. No primeiro texto o emprego dos

Olh@res, Guarulhos, v. 2, n. 1, p. 396-421. Maio, 2014. 
substantivos próprios Maria, Pedro e João denota a presença de interlocutores reais, de forma generalizada, a fim de respeitar a individualidade destes e mostrar que o problema é social. Há também, a preocupação de ressaltar que a alternância de parceiros pode trazer consequências graves e inesperadas. No segundo texto, a diferença de idade das personagens apresentadas e local onde estão mostram que o descaso com a saúde pública vai da infância a maior idade.

Quadro 3 - Análise dimensão global texto um e dois

\begin{tabular}{|l|l|c|}
\multicolumn{1}{|c|}{ Dimensão Global no eixo da coerência. } & \multicolumn{2}{c|}{ Gêneros Multimodais selecionados } \\
\cline { 2 - 3 } & HQs: Gravidez na Adolescência & $\begin{array}{c}\text { Cartum: A Saúde } \\
\text { Pública }\end{array}$ \\
\hline A) O universo da referência & $\mathrm{X}$ & $\mathrm{X}$ \\
\hline B) Unidade semântica & $\mathrm{X}$ & $\mathrm{X}$ \\
\hline C) Progressão do tema & $\mathrm{X}$ & $\mathrm{X}$ \\
\hline D) Propósito ou intenção mais específica & $\mathrm{X}$ & $\mathrm{X}$ \\
\hline E) A relevância informativa & $\mathrm{X}$ & $\mathrm{X}$ \\
\hline $\begin{array}{l}\text { F) As relações com outros textos, o que inclui, mais especificamente, } \\
\text { as alusões, as paráfrases, as paródias... }\end{array}$ & & $\mathrm{X}$ \\
\hline G) A direção argumentativa assumida & & \\
\hline H) As particularidades da superestrutura de cada gênero & & \\
\hline
\end{tabular}

O emprego das reticências, a vírgula e as interrogações, utilizados em todos os textos, juntamente com as características físicas das personagens confirmam que o tema é real, atual e do cotidiano dos alunos. Se observarmos as expressões faciais, poderemos notar que os interlocutores refletem nas posturas o que estão vivenciando.

Além disso, essa ideia é também reforçada pela seleção das cores utilizadas: rosa, azul, amarelo, verde, laranja, marrom, branco e preto presentes em todos os gêneros, com algumas exceções; em que o rosa representa ingenuidade, romantismo e fragilidade. $\mathrm{O}$ amarelo simboliza a alegria, descontração, vigor, juventude, poder de persuasão. $O$ azul retrata segurança, saúde e harmonia e o laranja a sensação de sucesso, desejo de ter algo; o preto, introspecção, emoções não desejadas e o branco, presente apenas no segundo texto: A saúde Pública, bem pertinente simboliza paz, verdade, calma.

Olh@res, Guarulhos, v. 2, n. 1, p. 396-421. Maio, 2014. 
Essas cores constroem todos os quadrinhos com algumas inovações como a introdução do roxo e marrom que simbolizam mistério, imaginação estabilidade (apenas para a personagem Pedro e no banco onde estão sentadas as pessoas, no primeiro e segundo textos). Interessante notar o domínio das cores verde e vermelho que simbolizam paixão, força, energia, esperança, equilíbrio, recomeço e a introdução do preto como alerta, presentes nos três textos, como consequência das escolhas anteriores que leva a introspecção, emoções não desejadas, presentes nos textos 1 e 2.

O tema é situado e apresentado de forma implícita ao leitor nos dois. Já se percebe o teor temático que será abordado, da direção argumentativa assumida. Além disso, como os enunciados presentes nos textos delimitam, direcionam o olhar do aluno tanto para a organização temática do texto quanto para seus esquemas de organização. Ao mesmo tempo situa o posicionamento das autoras. Subtende-se que o texto segue uma progressão temática preocupando-se com esse encadeamento, estruturado nessa perspectiva.

A linguagem multimodal, constituída por palavras, gestos, cores, expressões faciais, entre outras, utilizadas em ambos os textos, permite explorar não só a unidade semântica, como a progressão do tema, esquema de composição e relevância informativa. Ademais, a disposição desses elementos multimodais enfatizados pela linguagem verbal em ambos os textos, fortalecem o teor argumentativo dos textos.

Os enunciados também já indicam que há argumentos: "alternância entre parceiros", “a vida não tem prioridade" e onde eles estão no texto. O trabalho do leitor é ir a busca desses argumentos, fazendo uma leitura de localização; mas não apenas localizar, deve conseguir compreendê-lo. Compreensão pressupõe interação entre texto-autor-leitor. Segundo Cafiero (2010, p.86) "Ler é atribuir sentidos. E, ao compreender o texto como um todo coerente, o leitor pode ser capaz de refletir sobre ele, de criticá-lo, de saber como usá-lo em sua vida".

Para que o propósito do texto seja alcançado que é persuadir, conduzir o leitor a uma reflexão sobre o problema social elencado e refletir sobre a postura utilizada, questionando e criticando torna-se necessário, entender os

Olh@res, Guarulhos, v. 2, n. 1, p. 396-421. Maio, 2014. 
implícitos, as inferências, as vozes explicitadas pelas autoras, por meio dos argumentos apresentados por cada um dos textos.

Além do mais, para melhor entender esses gêneros multimodais argumentativos opinativos deve-se relacionar além dos aspectos globais destacados por Antunes (2010, p.56, 57), os diversos aspectos pontuais, como o uso dos dêiticos pessoais, espaciais e temporais e a relação dessas expressões com elementos do contexto; os efeitos de sentido (ênfase, reiteração, refutação, ambiguidade, humor, gradação, contraste) pretendidos pela escolha de determinada palavra, ou por certos recursos morfossintáticos e gráficos (reticências, diferentes cores, tamanhos e disposições das letras ou figuras, expressões faciais etc.).

Podemos ainda destacar os efeitos de sentido pretendidos pela transgressão de qualquer um dos padrões morfossintáticos e semânticos estabelecidos; a ocorrência de paráfrases e suas marcas indicativas; as marcas de ironia; as marcas do envolvimento do autor frente ao que é dito; a forma (direta ou indireta) de como o interlocutor está presente ou apenas suposto; as falas que se fazem ouvir; os implícitos ou 'vazios' de sentido", as marcas das especificidades de uso da oralidade ou da escrita; o nível de menor formalidade da linguagem utilizada; a presença de sinais que indicam a distribuição das informações em itens, em pontos distintos; aspectos da pontuação, da ortografia das palavras e da apresentação gráfica dos textos, subordinados, sempre, à coerência e à relevância; os diferentes usos $e$ correlações dos tempos e modos verbais; o nível de maior ou menor formalidade da linguagem utilizada; a presença de sinais que indicam a distribuição das informações sem itens, em pontos distintos e outras questões que se ponham em uma outra análise.

\section{Considerações finais}

As atividades interdisciplinares permitiram, em um primeiro momento, ao aluno a compreensão do gênero como evento social real capaz de atender suas necessidades de leitor; em um segundo momento, a apreensão do gênero como possibilidade de ler criticamente o mundo, a vida e atribuirlhes novos significados.

Olh@res, Guarulhos, v. 2, n. 1, p. 396-421. Maio, 2014. 
Ademais ao desejo de mostrar ao aluno que o texto discursivo é um modo de ação, uma forma em que as pessoas podem agir sobre o mundo e, especialmente, sobre os outros Fairclough (2001). Além disso, que em todo o discurso ecoa vozes do passado, que criam perspectivas novas da realidade social, permitindo uma abordagem multidimensional, (Bakhtin) e que ele, aluno pode através de um diálogo com diferentes gêneros e diferentes temas posicionar-se como cidadão crítico, como leitor/escritor/pesquisador, frente a problemas controversos de sua comunidade.

A análise mostrou, por um lado que o gênero multimodal é um excelente recurso linguístico de interação social, de poder, pois através de suas diferentes modalidades o locutor pode interagir com o seu interlocutor de maneira real, crítica e humorística, por meio de suas imagens fortes, seus traços sugestivos, proporcionando vantagens, mais facilmente do que o puramente linguístico; por conseguinte, penetram rapidamente na cognição social, modificando ideologias e paradigmas, como postula Maroun (2007, p.104). Por outro lado, que é necessário que as escolas, o MD e os professores, principais mediadores, preparem pessoas capazes de interpretar de maneira eficiente, textos mistos, verbais e não verbais; pessoas que sejam capazes de interagir com eles e por meio deles, sendo capazes de usá-los efetivamente, para atender suas necessidades sociocomunicativas. Sendo por um lado pesquisadores conscientes, críticos; por outro, lado produtores de informações capazes de, através de diálogos, gerar outras fontes de conhecimentos. Vale ressaltar que o interesse desse estudo não se restringe à construção de categorias, mas ao desejo de ver tais gêneros serem trabalhados como os demais, em sua forma, função e estilo, oportunizando assim o conhecimento de novos gêneros e novos saberes, além da apreensão de novas linguagens.

Olh@res, Guarulhos, v. 2, n. 1, p. 396-421. Maio, 2014. 


\section{Referências}

ANTUNES, Irandé. Análise de textos: fundamentos e práticas. São Paulo: Parábola Editorial, 2010.

BAKHTIN, Mikhail. Os gêneros do discurso. In: Estética da criação verbal. $4^{\text {a }}$ edição. Tradução: Paulo Bezerra. São Paulo: Martins Fontes, 2003

BRASIL. Secretária da Educação Fundamental. Parâmetros curriculares nacionais: terceiro e quarto ciclo do ensino fundamental: língua portuguesa/ Secretária de Educação Fundamental. Brasília: MEC/SEF, 1998.

CAFIERO, Delaine Bicalho. Boas Perguntas mobilizam capacidades de leitura. Guia da Alfabetização - Revista Educação, Belo Horizonte, p. 28 - 43, 01 jun. 2010.

CEREJA, Willian Roberto; MAGALHÃES, Thereza Cochar. Português Linguagens. São Paulo: Saraiva, 2012, v. 1,2 e 3.

DELL'ISOLA, Regina Lúcia Perét. Leitura: inferências e contexto sociocultural. Belo Horizonte: Formato Editorial, 2001.

. STV em texto textualização: o processamento da leitura de gêneros e avaliação da compreensão de textos. Belo Horizonte: UFMG, 2010.

DIONÍSIO, Ângela Paiva. Gêneros Multimodais e Multiletramentos. In KARWOSKI, Acir Mário GAYDECZKA, Beatriz. BRITO Karim Siebeneicher. (Org.) GÊNEROS TEXTUAIS: Reflexões e ensino. Rio de Janeiro: Lucerna, 2006.

FAIRCLOUGH, N. Discourse and social change. Cabridge: Polity Press, 1992. Discurso e mudança social. Coord. da trad. Izabel Magalhães, Brasília: editora Universidade de Brasília, 2001

GERALDI, João Wanderley et al. O texto na sala de aula. São Paulo: Ática, 2006.

KLEIMAN, Angela. Texto e Leitor: Aspectos Cognitivos da Leitura. 12a edição. Campinas, São Paulo: Pontes, 2008b.

MARCUSCHI, Luiz Antônio. Produção textual, análise de Gêneros e compreensão. São Paulo: Parábola Editorial, 2008.

MAROUN Cristiane Ribeiro Gomes Bou. O Texto Multimodal no Livro Didático de Português. In VIEIRA, Josélia Antunes, ROCHA, Harrison, FERRAZ, Janaina de Aquino. (org) Reflexões Sobre a Língua Portuguesa: Uma abordagem multimodal. Petrópolis, RJ: Vozes, 2007.

MENDONÇA, Márcia Rodrigues de Souza. Um gênero quadro a quadro: a história em quadrinhos. In DIONİSIO, Ângela Paiva, MACADO, Anna Rachel, BEZERRA, Maria Auxiliadora. (org) Gêneros Textuais \& Ensino. Rio de Janeiro: Lucerna, 2007.

MILLER, Carolyn R. Estudos sobre gênero textual, agência e tecnologia. Trad. Ana Regina Ferraz Vieira et al. Recife (PE): Ed. Universitária da UFPE, 2009.

PIMENTA, Sônia. Multimodalidade e semiótica social: o estado da arte. In MATTE Ana Cristina Fricke (org.). Lingua(gem), texto, discurso: entre a reflexão e a prática: Lucerna, 2007.

PINHEIRO, Najara Ferrari. A noção de gênero para análise de textos midiáticos. In: MEURER, José Luiz; MOTTA-ROTH, Désirée (Orgs.). Gêneros textuais. Bauru: EDUC, 2002.

ROJO, Roxane. Letramentos múltiplos, escola e inclusão social. São Paulo: Parábola Editorial, 2009.

Olh@res, Guarulhos, v. 2, n. 1, p. 396-421. Maio, 2014. 
Ressignificação da pesquisa escolar: o aluno-pesquisador, investigando e promovendo reflexão em seu meio, através de gêneros multimodais

SCHNEUWLY, Bernard; Dolz, Joaquim. Gêneros orais e escritos na escola. Trad. Roxane Rojo e Glaís Sales Cordeiro. Campinas: Mercado das Letras, 2004.

THOMPSON, J. Ideologia e cultura moderna: teoria social critica a era dos meios de comunicação de massa, Petrópolis: Vozes, 1995.

ZUIN, Poliana Bruno; REYES, Claudia Raimundo. O Ensino da Língua Materna: Dialogando com Vygotsky, Bakhtin e Freire. Aparecida, SP: Ideias \&Letras, 2010.

Olh@res, Guarulhos, v. 2, n. 1, p. 396-421. Maio, 2014. 